\title{
A New Epistemology of Nursing: A Post-Human Care?
}

\author{
Por Uma Nova Epistemologia da Enfermagem: Um Cuidar Post-Humano? \\ Por Una Nueva Epistemología de la Enfermería: Un Cuidado Poshumano?
}

Ana Paula Teixeira de Almeida Vieira Monteiro*

Manuel Curado**

\begin{abstract}
Background: The classical currents of $20^{\text {th }}$ century Humanism whose epistemological basis lies in the concept of logos and the notion that man is the measure of all things, which were adopted as the core of nursing care identity, no longer fit the parameters of hyper-technological/digital societies.

Objectives: To reflect on the impact of intensive biotechnology and cyborgization of the human body on building a new epistemology of nursing centered on the concept of Post-Human.

Main topics under analysis: Based on a conceptual framework and taking into account the theoretical references of nursing about caring, we intend to conduct an epistemological analysis of technology, Post-Humanism currents, and cyborg ontology.

Conclusion: The technological innovation and the cyborgization of the human body should translate into new concepts of care. Nursing research and education should contribute to develop a reflective and ethically responsible professional care, rather than focus on technopractical aspects and on a pragmatic and utilitarian knowledge.
\end{abstract}

Keywords: epistemology; humanism; nursing care; technological development

\section{Resumo}

Enquadramento: As correntes clássicas do bumanismo do século XX que tinham como base epistemológica $o$ logos e a ideia do homem como medida de todas as coisas, adotados pelo corpo teórico da enfermagem como o cerne da sua identidade, já não se adequam aos parâmetros das sociedades hipertecnológicas/ digitais.

Objetivos: Este artigo tem por objetivo partilhar uma reflexão sobre o impacto das biotecnologias intensivas e da cyborguização do corpo humano na construção de uma nova epistemologia de enfermagem, em que o conceito de Post-Humano é central.

Tópicos em análise: Através de um enquadramento conceptual e tendo em conta os referentes teóricos da enfermagem sobre o cuidar, pretende-se estruturar uma análise epistemológica sobre a tecnologia, as correntes de post-humanismo e a ontologia cyborg.

Conclusões: A inovação tecnológica e a cyborguização do humano devem traduzir-se em novos conceitos do cuidar. A investigação e a formação académica em enfermagem devem contribuir para o cuidado profissional reflexivo e eticamente responsável, em vez de se centrarem nas vertentes tecnopráticas e num conhecimento pragmático e utilitarista.

Palavras-chave: epistemologia; humanismo; cuidados de enfermagem; desenvolvimento tecnológico

\footnotetext{
* Ph.D., Post-doctoral student, University of Minho; Adjunct Professor, Nursing School of Coimbra, 3046-851, Coimbra, Portugal [anapaula@esenfc.pt]. Address for correspondence Coimbra, 3046-851, Coimbra, Portugal [anapaula@esenfc.pt]. Address for correspondence:
Escola Superior de Enfermagem de Coimbra, 3046-851, Coimbra, Portugal. Contribution to the article: Literature search; data collection; substantial contribution to conceptual analysis and reflection; article writing.

** Ph.D., Professor, University of Minho, Institute of Arts and Human Sciences, Gualtar Campus, 4710-057 Braga [jmcurado@ilch.uminho.pt]. Contribution to the article: Contribution to conceptual analysis.
}

\section{Resumen}

Contexto: Las corrientes clásicas del humanismo del siglo XX, que tenían como base epistemológica el logos y la idea del hombre como medida de todas las cosas y que el cuerpo teórico de la enfermería adoptó como núcleo de su identidad, ya no se ajustan a los parámetros de las sociedades hipertecnológicas / digitales.

Objetivos: Este artículo tiene como objetivo compartir una reflexión sobre el impacto de la biotecnología intensiva y la ciborguización del cuerpo humano en la construcción de una nueva epistemología de la enfermería, donde el concepto de poshumano es central.

Principales temas en análisis: A través de un marco conceptual y teniendo en cuenta las referencias teóricas de la enfermería sobre el cuidado se pretende estructurar un análisis epistemológico sobre la tecnología, las corrientes del poshumanismo y la ontología cíborg.

Conclusión: La innovación tecnológica y la ciborguización del humano deben traducirse en nuevos conceptos del cuidado. La investigación y la formación académica en enfermería deben contribuir al cuidado profesional, reflexivo y éticamente responsable en lugar de centrarse en las vertientes tecnoprácticas y en un conocimiento pragmático y utilitarista.

Palabras clave: epistemologia; humanismo; atención de enfermería; desarrollo tecnológico

Received for publication: 26.10 .15

Accepted for publication: 04.02.16 


\section{Introduction}

\section{Nursing and Technology}

The intensification of the globalization processes, the advances in health biotechnology and the digitalization of daily life entail a reconstruction of the epistemological references in nursing. This is important to answer questions which are still not yet structurally formulated because, first, it is necessary to build an entire path of thinking. Technology is intimately related to the establishment of nursing as a scientific profession at the turn of the $20^{\text {th }}$ century. The development and use of scientifically legitimized technologies contributed to differentiate between nursing and the lay and religious practices that until then characterized the concept of caring in health/disease processes. Therefore, technology has contributed to confer to this social practice - regarded as a woman's work oriented toward a systemized care - the status of socially recognized and regulated profession, with specific training requirements (Meyer, 2002).

However, the impact of new technologies on nursing care started being theoretically questioned after the 1970s, precisely when health technologies became more sophisticated. At the same time, as a result of this concern, an intense affirmation of the notion of person-centered care emerged, as well as the revival of the holistic perspective of caring as the essence of nursing. The central idea that nursing is about caring for people, rather than about treating and curing diseases (more typical of the biomedical model), is thus asserted based on the reflection about the acritical use of technologies, while feminist theories explore the symbolic construction and the power relations inherent to the affirmation of health technologies. The narratives about nursing care express the idea of reconciliation between male objectivity (expressed in scientific knowledge and technological artifacts) and female intuition and emotion which would characterize nursing care. This female-based mediation is the humanized mediation between physician and patient, between technology and caring. Therefore, from a symbolic perspective, the identification of nursing with hospital technologies expresses the male power hierarchy of medical professions and the gender differentiation, reinforcing the traditional invisibility of nursing care (Fairman \& D'Antonio, 1999).
Here, polarity is an underlying concept, which associates the feminine/nursing with the idea of nature/care/nourish and the masculine/medicine with the idea of power/control over nature/technology, positioning nursing as a female culture in conflict with technology, which is an essentially male culture. This perspective reinforces the idea of technology as a trend toward the dehumanization not only of patients but also of nurses, where technology emerges as threatening and potentially disruptive.

Thus, a new trend emerges in nursing sciences, which follow a humanist perspective of technology and classify it as non-human or non-natural, integrating a conceptual vision of a gap between human/ non-human and between nature/technology. This means that, considering the endless possibilities of technologization of all dimensions of the healthdisease process and the theoretical criticism to the paradigm of medical sciences which still largely sustains this technologization, nursing care is becoming increasingly theorized as the interface of humanization in the technology-client relationship (Meyer, 2002).

Empirical nursing studies have been following these transformations. Studies about the frontiers of care versus technology usually focus on intensive care or emergency units, particularly on the relationship between nurses and critically ill patients. These cutting-edge services differ from other health services in the centrality of hyper-specialized care and the use of sophisticated technology for diagnostic and therapeutic procedures. In fact, intensive care units, emergency units, recovery units and some cuttingedge surgery units are at the top of the technological hyper-complexity of the human body-machine interface. These studies show that the association between cutting-edge technologies and nursing care does not translate into a mere transfer of highintensity technological applications and systems and their use in clinical practice (e.g., the use of sophisticated advanced life support equipment). It implies a transformation of the available technology. Nurses have to reconfigure and transform invasive technologies in their clinical practice, so that they can have a positive impact on the care receivers, thus trying to maintain the essence of nursing (personcentered care). In a 6-month ethnographic study in an intensive care unit to analyze the relationship between nursing care and technologies, Crocker and 
Timmons (2009) found that novice nurses tend to take on an approach to biomedical technologies focused on the tasks and on the immediate utilitarianism of technological artifacts. However, expert nurses, who are more specialized in intensive care, tend to use hard technologies in a slightly different way, using and transforming them into a nursing technology, i.e. a human care technology.

This means that the impact of technologies on nursing care goes substantially beyond the effective use of technological artifacts and the handling of sophisticated equipment to provide care in hyper-complex environments. It requires specific knowledge, systematized technical skills and a very specific system of thought built upon the objectives of the interventions, the choices made in clinical settings and the decisions on priorities in health care provision, taking into account the care receivers.

The use of technology in nursing while caring for critically ill patients in intensive care also implies caring for the machines. In clinical nursing settings, machines, especially those used in advanced life support, "eventually become another target of nursing care, because, like patients, they also need to be touched, cared for and assisted" (Silva et al., 2009, p. 211).

Caring for machines is therefore assumed as a nursing care, since nurses are highly aware that there is a full symbiosis between human body and machine and that survival depends entirely on the functionality of the technological apparatus.

More than the anthropomorphization of technological artifacts, the idea that nursing care involves the body-machine symbiosis is precisely at the very heart of the frontier and the hybridism between human and technology. It is now a matter of caring for a hybrid body, a frontier body, giving rise to all possible assumptions on the limits between human, nonhuman and inhuman conditions.

Therefore, the radical technologization of caring implies that, at the same time as the notions of humanism or bumanitude are vigorously reaffirmed in the area of nursing because of technology, the conceptual limits of what is human are vanishing. The humanisms of the $20^{\text {th }}$ century, epistemologically based on the concept of logos and the idea of man as the measure of all things and adopted as the core of nursing care identity since Florence Nightingale, no longer fit the parameters of hyper-technological and digital societies. This traditional humanism, inspired by a book culture and the canons of classical western philosophy, has become obsolete in light of the advances in neurosciences and genetics that brought new dimensions to the old concepts of reason, conscience and emotion (Chavario-Alfaro, 2015).

\section{Development}

\section{A Post-Human Nursing Care}

At the essence of the association between biological and technical evolution, the concept of PostHuman represents a trend that suggests not only an ontological transmutation of the human condition, but also the development of new forms of life beyond the traditional boundaries between natural and artificial (Fukuyama, 2003).

In conceptual and ontological terms, Post-Humanism is a trend that includes a significant number of movements and schools of thought, passing through some gray areas. At the end of the 1990s, Post-Humanism started to be investigated from a philosophical perspective in a comprehensive attempt to integrate the newly acquired awareness of the limits of the anthropocentric and humanistic assumptions that guided the classical philosophical construction (Ferrando, 2013).

In short, and despite the polysemy of the term, the various philosophical currents of Post-Humanism had in common the questioning of the classical and modern notion of humanism based on the Cartesian ego cogito and the rejection of the underlying dichotomous categories, such as mind-body, subjectobject and culture-nature, since all are based on anthropocentrism and on the idea of the instrumental rationality of technology.

Therefore, the Post-Human condition means the end of the notion of a person-centered universe, which emerged in the Renaissance. In other words, it means "the end of humanism, this long held belief in the infallibility of human power over nature and the arrogant belief in our superiority and uniqueness" (Pepperell, 2003, p.171). In a simplified way, it can be defined as the condition in which humans and intelligent technology are becoming irreversibly intertwined in a merger between humanity and machines and in the emergence of an undifferentiated hybridism, a new categorization of the Human. 
However, although understanding the historical and ontological dimension of technology is essential to analyze the various Post-Humanism currents, the emerging issues on the conceptual redefinition of the Human and the Post-Human cannot be reduced to the theoretical references of the debate on technology. Well beyond the techno-essentialism or the notion that technology is an instrumental tool to obtain advantages or control nature, technology is asserted as an integral part of the human being and of the very essence of the human condition. Underlying the notion that humankind, since its beginning, is a product of its technique and that the technological artifacts and prostheses, i.e. the production and intentional use of instruments, define hominization is the assumption that the technical ability allowed expanding the basic biological potential of the human species, controlling nature and enabling survival in a hostile environment. This notion makes it difficult to distinguish between Human and PostHuman (Braidotti, 2013). These terms are mutually constitutive and cannot exist independent of each other.

In his phenomenological approach, Borgmann (1984) believes that technology is the typically modern way to deal with the world, consisting in a paradigm or a characteristic pattern, intrinsic to daily life, which can be accurately described and has a specific impact on our relationships with the others and the surrounding environment. This critical perspective focuses on how technology affects human relationships at all levels: political, social, and aesthetic. The technological attitude of modernity has resulted in disintegration, decontextualization and production of technological devices and artifacts for consumption and leisure. These technological devices, which can either be natural (such as plants or animals for human use and consumption) or artificial (such as artifacts), as well as all social and cultural objects, are narrowed down to instrumental resources for circumstantial purposes and reduced to focal things of practical dimension (Borgmann, 1984).

The concept of technology as a mode of revealing existence (Heidegger, 1977) allows coming closer to its most profound ontological meaning in a contemporary context where technology has been narrowed down to this concept of mere technicalinstrumental apparatus for the utilitarian production of technological artifacts and environments.
Technology is not limited to the essentialist notion of technoscience; it is rather a principle of construction of the world under certain specific conditions and expresses a way of being in the world, a positioning process towards reality and a way of thinking.

The recent scientific advances in biotechnology, robotics, information technology, genetics and nanotechnology place the issue about the human nature and the characteristics of the human being at the center of the debate. The definition of what is human is increasingly more focused on the functional contents than on the form: the human condition (the sense of humanity, bumanitude) is now defined by how a species operates, i.e. how the species processes information, rather than by morphology or biological substrate. The human body is the original prosthesis from which to build the identity and the processes of conscience, and, as such, it can be replaced by other prosthetic processes. In this PostHuman notion, there are no fundamental differences or absolute demarcations between existence in a body and computer simulation, between cybernetic mechanisms, artificial intelligence and biological bodies, between robotic teleology and human objectives (Hayles, 1999). If the focus is now on information as the essence of all intelligent systems, and if materials and bodies are mere substrates that support vital information, then there is little difference between human beings, artificial intelligence systems or beings with other forms of intelligence, such as animals (Hayles, 1999). In other words, human exceptionalism is dead (Braidotti, 2013).

\section{Caring for a Cyborg Body}

Cyborg ontology has special relevance when discussing the emergence of new forms of scientific knowledge in nursing and the construction of a Post-Human care. The term cyborg (short for cybernetic organism) was first used in the scientific literature in the 1960s, in the midst of the race to space exploration, to designate the technological devices and mechanical adaptations coupled to the body of astronauts to increase the unconscious and self-regulatory operation of organic systems, making it possible to survive in a lethal physical environment (Clynes \& Kline, 1960).

According to Haraway (1991), the concept of cyborg emerges as an epistemological and ontological rupture from essentialist categorizations, breaking down barriers and allowing for combinations, ambivalence 
and hybridisms, both in relation to the human/nonhuman, biological organism/machine and natural/ artificial categories, but also to the distinctions of race, class, gender or age.

The notion of cyborg has been assumed as a transgressive border in arts, technoscience, innovation, politics, science fiction or philosophical research. But it is within the narrow margins of the health care practice that cyborgization processes of the body and the human face their most radical materialization. Current nursing is built upon the confrontation with these hyper-technological processes present from intrauterine life until death and postmortem processes. The current computerization of all caring processes applied to Nursing also contributes to the cyborgization of care. The concept of metaphoric cyborgs refers to connections between human bodies, machines and computer systems which are not permanent or irreversible and can be easily disabled (Hayles, 1999). The digitalization of the body in health care poses other challenges to nursing, including the acknowledgement of digital care as a nursing intervention (cyber nursing) or of the fact that holistic care incorporates the concept of techno-Self and virtual identities (Salzmann-Erikson \& Eriksson, 2015). Nursing care digital platforms are a sociotechnical system that expresses a particular way of understanding both disease and care, narrowed down to the domain of information networks and systems of response (expected to be quick and effective) to standardized symptoms. These are not mere axiologically neutral computer applications.

The almost routine use of increasingly sophisticated pacemakers, cochlear implants, bionic prostheses, intraocular lenses, neuromodulation technologies, in vivo biosensors in daily clinical practice, as well as a wide range of health-related digital artifacts have transformed patients and nursing care. To some extent, nurses are permanently caring for cyborgs in their daily routines.

Haddow, King, Kunkler, and McLaren (2015), in a study on the impact of living with implanted biosensors in a sample of prostate cancer patients, use the term everyday cyborgs to define the condition of individuals experiencing technological hybridism on a daily basis. Additionally, the more perfect and technologically advanced is the bionic component integrated in the body, the lower will be the subject's perception that it is a non-bodily artifact or a non- human incorporated fragment. Bionic prostheses, sensors and implants tend to be fully incorporated by the subject to the extent that they contribute to the organized functioning of the biological system, by increasing and strengthening abilities or bridging gaps of vital homeostasis, improving the individual's quality of life or even allowing him/her to survive. The more intimate and automatic are the technological adaptations inside the body, the more evident is the cyborg condition. Mechanical parts and technological prostheses become parts of the body and the person in the same way as a functional human organ (Haddow, King, Kunkler, \& McLaren, 2015).

In fact, the cyborgization processes of the human are today at the core of health care (Meyer, 2002). These processes can be restorative (allowing to restore biological functions as in pharmacological technology), normalizing (with reconstructive surgeries, bionic limbs), reconfiguring, when they create Post-Human creatures that are similar to human beings but, at the same time, completely different (e.g., the systematic reconfiguration of the immune system through vaccination) or enhancing, when they create creatures with more potential, substantially more capable than the natural or original human being (as in the use of high-technological prosthesis, exoskeletons or brain-chip-interfaces).

These processes, which began with the emergence of modern medicine at the dawn of technical rationality, are now completely trivial. The beginning and end of human life, the possibilities of extending life through aggressive biotechnologies, the reconfiguration of biologically predetermined standards or the limits of body plasticity are issues that pose new questions about the meaning of person-centered care.

Some authors argue that the increase of human abilities through digital technologies, genetics, robotics, cutting-edge nanotechnologies or smart drugs indicates not only that the human body is improving, but also that is the human being as a species is undergoing significant transformations, reinventing the existential biological substrate of what is considered human and implying the transcendence of the body and an evolutionary leap of the human species.

Post-Human thinking implies not only reconsidering the identity of the human being without definitive gaps as other non-humans (animals, machines, objects, digital artifacts, systems, the environment) 
but also building a compound identity, focused on the relational ability. This dimension encompasses the dimensions of bioethics, political science, neuroscience, gender studies, as well as the epistemological foundations of nursing science.

Here, all dimensions of nursing care can be reduced to activities with a purely technical and instrumental logic. In a frenzied sanitary dystopia, the very notion of humanized nursing care would no longer make any sense as it is fully integrated into the notion of highly differentiated technological care. Nowadays, the human body emerges as a tradable artifact, in the pursuit for a perfect health in a perfected body within a bioeconomics of the body at the global scale (LaFontaine, 2014). Nursing care integrate a utilitarian perspective and are part of a wider system which provides a range of services aimed at improving the body and producing better health outcomes, wellbeing and longevity at any price.

Despite this, there is also the creative possibility of reorganizing nursing thinking by integrating the new frontiers of the Post-Human without losing the references of caring. The paradigm of cyborg ontology - fully assumed as a construct of nursing may be the starting point for person-centered care and aggressive biotechnologies to go beyond the gap, allowing the meaning of nursing care to be updated and contextualized.

\section{Conclusion}

The assumption underlying this theoretical reflection is the idea that global health systems and nursing care are already facing a Post-Human reality of radical biotechnological intensity, in which digitalization plays a central role in care provision. The concepts of health and well-being already overlap in processes to improve or increase the capacities of the human body and the human being, through the contributions of new technologies and the possibility, now quite real, of improving, modifying and redesigning the human being.

In recent decades, health biotechnologies, associated with information and communication technologies, have had an exponential dissemination in the social fabric, profoundly changing the way in which health care are understood and implemented. High intensity health care technologies have become more fluid, easy to use and accessible; they have left the hospital settings and have entered the daily lives of millions of patients, within their homes and communities. At the same time, the technological evolution was so intense within specialized settings (hospital environment) that the threshold of the possibility of intervening in critical situations, i.e. at the border between life and death, has radically expanded, posing ethical dilemmas concerning the practical applicability of innovative technological possibilities.

The current debates on the interface between technology and nursing are based on a new understanding of the central tenets of technology as a phenomenon and on a reflective approach to the concept of caring, focusing on the challenges that arise from the constant tension between desired and unpredictable outcomes of the application of technology in health (Barnard, 2015). Paradoxically, the technicist approach decreases the effectiveness and the outcomes of the care provided, even those strictly related to technological manipulation. On the other hand, the predominance of the strictly technical rationality excludes the aesthetic and performative components which are intrinsic to the nursing care practice, being unable to capture the singularity, instability, ambiguity and conflict of values that characterize the health care practice (Moya, 2013).

This disjunction leaves out some assumptions (for being meaningless, according to the conceptual framework of technical rationality) related, for example, to the ethical and ideological dimensions necessarily involved in caring. This means that the performance based on a strictly instrumental logic of technical rationality, even in hyper-technological settings, does not correspond to the competent nursing care practice, because it is rooted in the reflection in action, which generates the professional (practical) knowledge that empowers for a competent care provision (Taylor, 2010).

Between the classical nursing narratives about person-centered care and the future of technological globalization, philosophical research can contribute to the development of nursing in hyper-complex settings, allowing us to definitely overcome the dichotomy between technique and human, between bodies and machines, between theory and practice.

Future nurses must have a strong technical knowledge to be able to handle biomedical technologies, knowledge of Biomedical Engineering 
and Information Technology, as well as the capacity to adapt to the rapid technological evolution. However, the lack of a self-reflective possibility, the urgency of high intensity technological training for a global market, the need for a performance using economics-based productivity indicators (where nursing knowledge and research are associated with utilitarian indicators of technological profitability) may lead to the alienation of the notion of nursing care. Advanced research and academic training in nursing should contribute to promote both autonomy and a reflective professional and ethically responsible provision of care, instead of focusing on the essentially technopractical aspects and on a pragmatic and utilitarian knowledge.

\section{References}

Barnard, A. (2015). Ambivalence and uncertainty: Reflections on technological advancements in nursing. In Abstracts $19^{\text {th }}$ International Philosophy of Nursing Society (IPONS) Conference, Stockholm, Sweden, 2426 August 2015. Stockholm, Sweden: Karolinska Institutet.

Borgmann, A. (1984). Technology and the character of contemporary life. Chicago, USA: University of Chicago Press.

Braidotti, R. (2013) The posthuman. Cambridge, England: Polity Press.

Chavario-Alfaro, G. (2015). El posthumanismo y los cambios en la identidad humana. Revista Reflexiones, 94(1), 97107. Retrieved from http://revistas.ucr.ac.cr/index.php/ reflexiones/article/view/20882/21024

Crocker, C., \& Timmons, S. (2009). The role of technology in critical care nursing. Journal of Advanced Nursing, 65(1), 52-61. doi: 10.1111/j.1365-2648.2008.04838.x

Fairman, J. A., \& D’Antonio, P. (1999). Virtual power: Gendering the nurse-technology telationship. Nursing Inquiry, 6, 178186. doi: 10.1046/j.1440-1800.1999.00032.x

Ferrando, F. (2013). Posthumanism,transhumanism, antihumanism, metahumanism, and new materialisms differences and relations. Existenz, 8(2), 26-32. Retrieved from https://www.bu.edu/paideia/existenz/volumes/Vol.82Ferrando.pdf

Fukuyama, F. (2003). Our posthuman future: Consequences of the biotechnology revolution. London, England: Profile Books.
Haraway, D. (1991). Simians, cyborgs, and women: The reinvention of nature. New York, USA: Routledge.

Hayles, K. (1999). How we became posthuman: Virtual bodies in cybernetics, literature, and informatics. Chicago, USA: University of Chicago Press.

Haddow, G., King, E., Kunkler, I., \& McLaren, D. (2015). Cyborgs in the everyday: Masculinity and biosensing prostate cancer. Science as Culture, 24(4), 484-506. doi:

$10.1080 / 09505431.2015 .1063597$

Heidegger, M. (1977). The question concerning technology. New York, USA: Harper.

LaFontaine, C. (2014). Le corps-marché: La marchandisation de la vie bumaine à l'ère de la bioéconomie. Paris, France: Seuil.

Meyer, D. E. (2002). Como conciliar humanização e tecnologia na formação de enfermeiras/os?. Revista Brasileira de Enfermagem, 55(2), 189-195. Retrieved from http://www. scielo.br/pdf/reben/v55n2/v55n2a13.pdf-

Monteiro, A. P. (2016). Cyborgs, biotechnologies, and informatics in health care: New paradigms in nursing sciences. Nursing Philosophy, 17(1), 19-27. Retrieved from http://www.scielo. br/pdf/reben/v55n2/v55n2a13.pdf

Moya, J. L. (2013). Prácticas educativas y práctica de cuidados enfermeros desde una perspetiva reflexiva. Revista de Enfermería, 15. Retrieved from https://www.uclm.es/ab/ enfermeria/revista/numero\%2015/numero15/pr\%E1ctica_ educativa_y_pr\%E1ctica_de.htm

Pepperell, R. (2003).The post-buman condition: Consciousness beyond the brain. Bristol, England: Intellect Books.

Salzmann-Erikson, M., \& Eriksson, H. (2015).The rise of the avatar: Virtual dimensions of 'the human' in nursing science. Nordic Journal of Nursing Research, 35, 158-164. Retrieved from http://www.rkh.se/PageFiles/4946/The\%20Rise\%20 of $\% 20$ the\%20Avatar.pdf

Silva, R. L., Kaczmarkiewicz, C., Cunha, J., Meira, I., Figueiredo, N., \& Porto, I. (2009). O significado da tecnologia na assistência de enfermagem em pós-operatório imediato de cirurgia cardíaca. Revista da Sociedade de Cardiologia do Estado do Rio de Janeiro, 22(4), 210-218. Retrieved from http:// www.rbconline.org.br/wp-content/uploads/a2009_v22_ n04_02rcarlos.pdf

Taylor, B. J (2010). Reflective practice for healthcare professionals ( $3^{\mathrm{a}}$ ed.). Maidenhead, England: Open University Press. 
